\title{
Dynamic Model of Slag Foaming in Oxygen Steelmaking Converters
}

\author{
Paretosh MISRA, Brahma DEO and R. P. CHHABRA ${ }^{1)}$
}

Department of Materials and Metallurgical Engineering, Indian Institute of Technology, Kanpur 208016, India.

E-mail: bdeo@iitk.ernet.in 1) Department of Chemical Engineering, Indian Institute of Technology, Kanpur 208016, India.

(Received on March 18, 1998; accepted in final form on July 22, 1998)

The foaming and emulsification of steelmaking slags can be analyzed in terms of an emulsion number which is defined as the ratio of the velocity of gas bubbles and that of metal droplets present in slag at any given stage of the blow. An improved procedure is suggested to evaluate the viscosity of gas-slag foam at high gas void fractions. The calculated velocity of gas bubbles in foaming slags is verified using the experimental results reported in literature. A critical comparison is also made with the other approaches available in the literature. It is shown that the emulsion number is directly related to foaming conditions. A dynamic model of slag foaming is developed on the basis of the bubble and droplet velocities, changing slag composition and temperature and the continuous reduction of iron oxide content of slag during the main blow period. Combined effects of lance nozzle design and blowing regime on slag foaming are discussed.

KEY WORDS: steelmaking; foaming; emulsion; metal droplets; bubbles; converter.

\section{Introduction}

The phenomenon of slag foaming and emulsification in oxygen steel making converters is of great practical significance during the middle blow period (i.e., between $30-70 \%$ of blow time). The slag samples collected during this period have revealed the presence of entrapped gas bubbles, metal droplets of varying sizes and also undissolved lime particles coated with a thin layer of dicalcium silicate. In spite of the inhomogeneities present in slag, the decarburization rate during middle blow period is nearly constant. The foaming of slag is such that lance tip is fully submerged in the foam. Only when the foaming becomes excessive, slopping occurs, which in turn leads to undesirable loss by entrainment of iron as iron droplets and $\mathrm{FeO}$ from the converter. In our previous work, ${ }^{1)}$ the (slag)-(metal droplet)-(gas) emulsion was characterized through a dimensionless parameter, namely, Emulsion number En, defined as:

$$
\begin{aligned}
& \mathrm{En}=\frac{\text { Mean residence time of metal droplets in slag, }\left(\tau_{\mathrm{d}}\right)}{\text { Mean residence time of gas bubbles in slag, }\left(\tau_{\mathrm{b}}\right)} \\
& =\frac{\left\langle\left(h / V_{\mathrm{d}}\right)\right\rangle}{\left\langle\left(h / V_{\mathrm{g}}\right)\right\rangle}=\frac{V_{\mathrm{g}}}{V_{\mathrm{d}}}
\end{aligned}
$$

The settling velocity of metal droplets $V_{\mathrm{d}}$ was calculated by employing the expression proposed by Gal-Or and Waslo $^{1,2)}$ :

$$
V_{\mathrm{d}}=\frac{\left(\rho_{\mathrm{m}}-\rho_{\mathrm{sg}}\right) g d_{\mathrm{m}}^{2}}{18 \mu_{\mathrm{sg}}} \Delta_{\mathrm{sm}}
$$

where the factor $\Delta_{\mathrm{sm}}$ accounts for the inter-particle interactions of ensemble of droplets $\left(\Delta_{\mathrm{sm}}>1\right)$

$$
\begin{aligned}
& \Delta_{\mathrm{sm}}= \\
& \frac{3 \mu_{\mathrm{sg}}\left(1-\phi_{\mathrm{m}}^{1 / 3}\right)\left(1-\phi_{\mathrm{m}}^{5 / 3}\right)+\left[3-\frac{9}{2}\left(\phi_{m}^{1 / 3}-\phi_{\mathrm{m}}^{5 / 3}\right)-3 \phi_{\mathrm{m}}^{2}\right] \mu_{\mathrm{m}}}{2 \mu_{\mathrm{sg}}\left(1-\phi_{\mathrm{m}}^{5 / 3}\right)+\left(3+2 \phi_{\mathrm{m}}^{5 / 3}\right) \mu_{\mathrm{m}}}
\end{aligned}
$$

and the average diameter of droplets, $d_{\mathrm{m}}$, can be calculated ${ }^{1.3)}$ by knowing the limiting diameter of droplets, $d_{\text {lim }}$, ejected from the jet impact zone

$$
d_{\mathrm{m}}=0.2 d_{\mathrm{lim}}
$$

where

$$
d_{\mathrm{lim}}=5.513 \times 10^{-6}\left[10\left(\frac{d_{\mathrm{t}}}{x}\right)^{2} p_{\mathrm{at}}\left\{1.27\left(\frac{p_{\mathrm{o}}}{p_{\mathrm{at}}}\right)-1\right\} \cos \theta\right]^{1.206}
$$

The symbols are defined and explained in Nomenclature. The term $\mu_{\mathrm{sg}}$ represents the viscosity of slag in the presence of gas bubbles. In our previous work, ${ }^{1)}$ the value of $\mu_{\mathrm{sg}}$ was calculated by using the equation

$$
\mu_{\mathrm{sg}}=\frac{2 \mu_{\mathrm{s}}\left(1-\phi_{\mathrm{g}}\right)}{3\left(1-\phi_{g}^{1 / 3}\right)}
$$

For a typical case of steelmaking slag the values are: viscosity of slag $\left(\mu_{\mathrm{s}}\right) \sim 0.079 \mathrm{~Pa} \cdot \mathrm{s}$; mass of slag $\sim 23000$ $\mathrm{kg}$; surface tension of slag $\left(\sigma_{\mathrm{s}}\right) \sim 0.469 \mathrm{~N} / \mathrm{m}$; density of slag $\left(\rho_{\mathrm{s}}\right) \sim 2991.4 \mathrm{~kg} \mathrm{~m}^{-3}$; gas void fraction $\left(\phi_{\mathrm{g}}\right) \sim 0.9$, viscosity of metal $\left(\mu_{\mathrm{m}}\right) \sim 0.00568 \mathrm{~Pa} \cdot \mathrm{s}$, fraction of metal droplets in slag $\left(\phi_{\mathrm{m}}\right) \sim 0.00020$, and diameter of metal droplets $\left(d_{\mathrm{m}}\right) \sim 0.024 \mathrm{~m}$, density of metal droplets $\left(\rho_{\mathrm{m}}\right) \sim$ $7000 \mathrm{~kg} \mathrm{~m}^{-3}$. The value of $\mu_{\mathrm{sg}}$ was calculated as 0.151 $\mathrm{Pa} \cdot \mathrm{s}$ and from Eq. (2) the corresponding value of $V_{\mathrm{d}}$ was found to be $20.95 \mathrm{~m} / \mathrm{s}$. Subsequently, an extensive literature survey has shown that this order of magnitude of $V_{\mathrm{d}}$ is actually much greater than the reported values 
in laboratory experiments; for example, ${ }^{4)}$ measured values of $V_{\mathrm{d}}$ is only in the range of $0.2 \mathrm{~m} / \mathrm{s}$. Therefore, further refinements in our previous analysis are necessary.

A simple calculation (considering the volume ratio of slag foam to available converter volume) will show that in the middle blow period the gas void fraction in slag foam may range from $0.7-0.95$. At such high gas void fractions the viscosity of slag-gas continuous phase is expected to increase substantially. Due to the lack of available space at high gas void fraction and high viscosity of slag foam, the motion of liquid metal droplets would be severely restricted. The impediment in the settling rate of metal droplets is usually called "wall effect". In our previous work the wall effects were neglected and this presumably resulted in the unrealistic values of droplet velocity of the order of $20 \mathrm{~m} / \mathrm{s}$. Reassessment of droplet velocity, $V_{\mathrm{d}}$, is one of the aspects of discussion of this paper. The experimental values of bubble velocity in slag-gas foams as reported in literature, are also verified. New values of emulsion number are calculated for the conditions of interest in oxygen steelmaking converters where the carbon containing metal droplets fall through the gas-slag foam and simultaneously reduce the $\mathrm{FeO}$ in slag to molten iron and generate additional gas due to the reaction $\mathrm{FeO}+(\mathrm{C}) \rightarrow \mathrm{Fe}+(\mathrm{CO})_{\mathrm{g}}$. After verifying bubble and droplet velocities, a dynamic model of slag foaming is developed which can be used to predict the possibility of excessive slopping. Nozzle designs and the corresponding blowing regimes must be chosen carefully to minimize the possibility of slopping. As far as known to us, this is the first attempt at developing such a dynamic model of slag foaming in oxygen steelmaking converters on the basis of fundamental considerations and in which the contributions of gas, slag and metal are considered simultaneously.

\section{Rationalization of the Effect of Viscosity of Slag Foam on Settling Velocity of Metal Droplets}

Eilers $^{5)}$ proposed an expression to calculate the viscosity of a suspension with a high solid phase concentration

$$
\mu_{\mathrm{eff}}=\mu_{\mathrm{s}}\left[1+\frac{1.25}{\left(1-\phi / \phi_{\max }\right)}\right]^{2}
$$

In our system it is primarily the gas bubbles which are dispersed in liquid slag. In view of the immobilization of the bubble surface by impurities, which suppresses the internal circulation inside the bubbles, Eq. (5) can be used for gas-liquid system as a first approximation. Further, for solid spheres of same size, $\phi_{\max } \sim 0.74$ (in Eq. (5)). In the case of gas bubbles, however, in spite of their immobilization, the gas bubbles in foam can still deform and $\phi_{\mathrm{g}, \max }$ can achieve values close to unity. Thus if $\phi_{\max }$ in Eq. (5) is approximated to be unity then for a slag-gas continum $\mu_{\mathrm{sg}}$ can be expressed as:

$$
\mu_{\mathrm{sg}}=\mu_{\mathrm{s}}\left[1+\frac{1.25}{1-\phi_{\mathrm{g}}}\right]^{2}
$$

Accordingly, $\Delta_{\mathrm{sm}}$ can now be calculated from Eq. (3) by

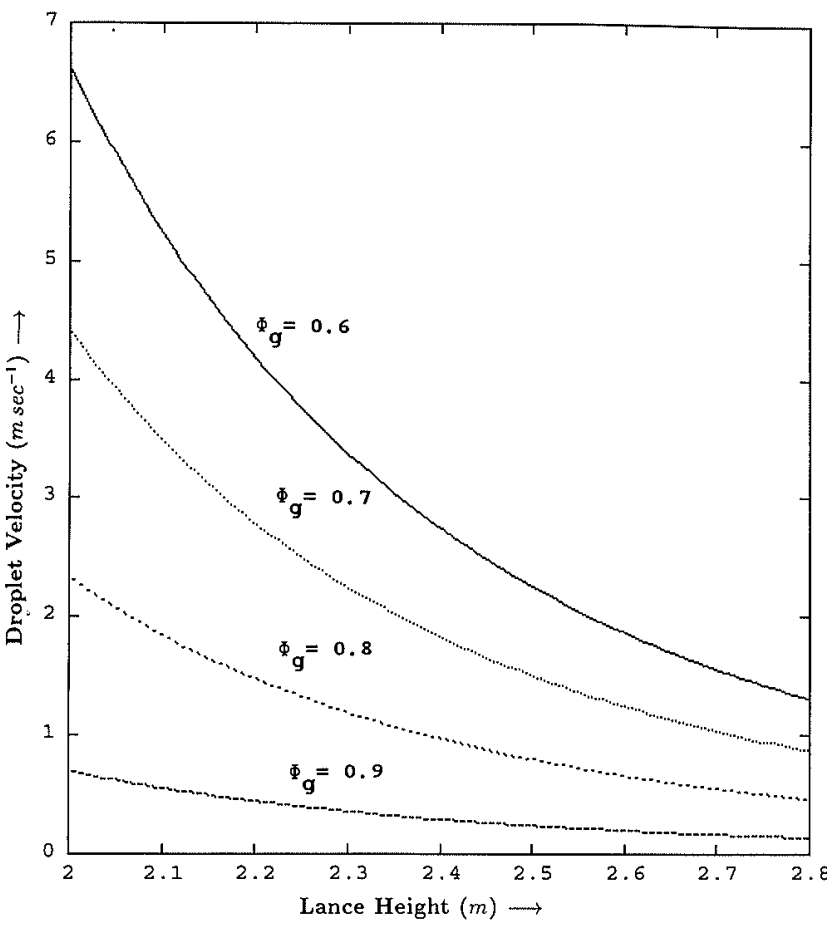

Fig. 1. Droplet velocity in gas-slag foam at different lance heights; gas void fraction values chosen are in the range $0.6-0.9$.

substituting the value of $\mu_{\mathrm{sg}}$ from Eq. (6). For a known value of $\mu_{\mathrm{sg}}$ we can now calculate the droplet velocity $\left(V_{\mathrm{d}}\right)$ from Eq. (2). Again, for the typical case: $\mathrm{CaO} \sim 45 \%, \quad \mathrm{FeO} \sim 15 \%, \quad \mathrm{SiO}_{2} \sim 20 \%, \quad \mathrm{MnO} \sim 8 \%$, $\mathrm{MgO} \sim 4 \%, \mathrm{Al}_{2} \mathrm{O}_{3} \sim 3 \%, \mathrm{CaF}_{2} \sim 1.4 \%, \mathrm{P}_{2} \mathrm{O}_{5} \sim 3.6 \%$ ), temperature $\sim 1873 \mathrm{~K}$ and gas void fraction $\sim 0.90$, the value of $V_{\mathrm{d}}$ for a lance height of $2 \mathrm{~m}$ is $0.2 \mathrm{~m} / \mathrm{s}$. Droplet diameter actually depends upon lance height. Using Eq. (2), $V_{\mathrm{d}}$ is plotted as a function of lance height in Fig. 1. If these values of $V_{\mathrm{d}}$ are compared with that reported in our previous work, ${ }^{1}$ it would be observed that the new value of $V_{\mathrm{d}}$ is smaller by approximately a factor, $\psi$

$$
\psi=\frac{3\left(1-\phi_{\mathrm{g}}^{1 / 3}\right)\left(2.25-\phi_{\mathrm{g}}\right)^{2}}{2\left(1-\phi_{\mathrm{g}}\right)^{3}}
$$

For $\phi_{\mathrm{g}}=0.90, \psi$ equals 94.3 ; droplet velocity according to the present work is therefore smaller by a factor of nearly 100 . The resulting new values of droplet velocity seem to be fairly close to the reported experimental values.

\section{Comparison and Verification of Calculated Bubble Velocity}

Bubble velocity is calculated using the same expression as suggested previously, ${ }^{1)}$ i.e.,

$$
V_{\mathrm{g}}=\frac{\left(\rho_{\mathrm{sm}}-\rho_{\mathrm{g}}\right) g d_{\mathrm{b}}^{2}}{12 \mu_{\mathrm{sm}}}\left(1-\phi_{\mathrm{g}}^{1 / 3}\right)
$$

where average bubble diameter is calculated using the following expression ${ }^{6}$

$$
d_{\mathrm{b}}=\frac{1}{2}\left[2\left(\frac{6}{\varepsilon}\right)^{1 / 3} \frac{\sigma}{0.52 g\left(\rho_{\mathrm{g}} \rho_{\mathrm{sm}}^{2}\right)^{1 / 3}}\right]^{1 / 2}
$$




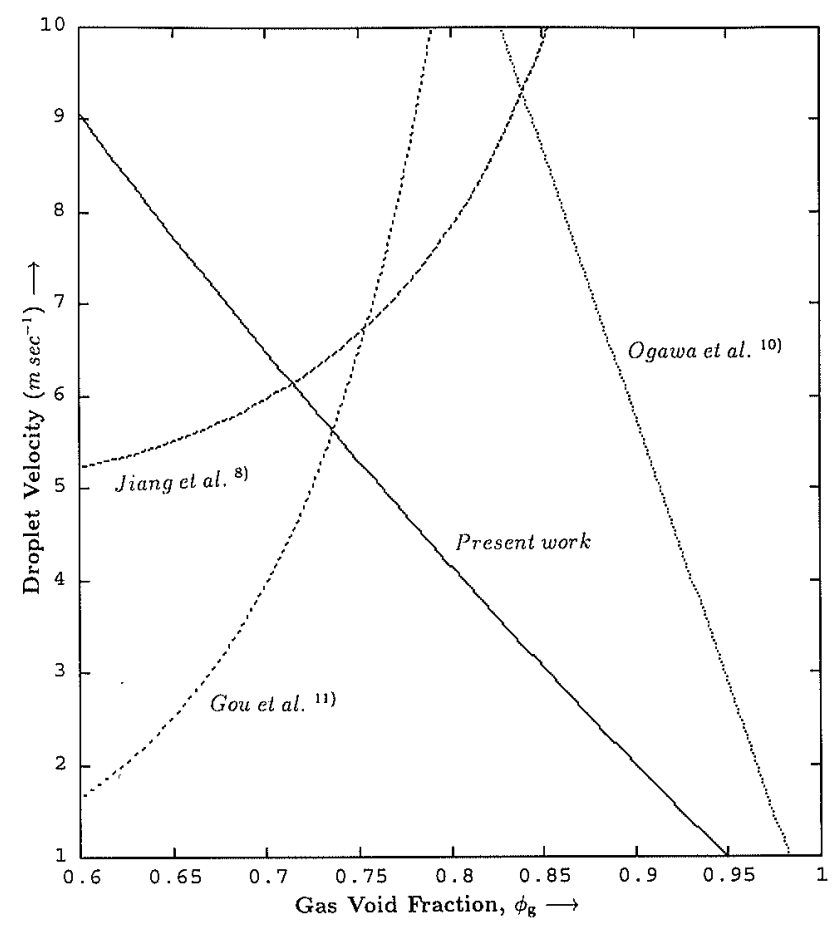

Fig. 2. Estimated bubble velocity in foaming slags according to present work and the equations proposed by other investigators ${ }^{8,10,11)} ; \phi_{\mathrm{g}}$ is assumed 0.9 .

It is interesting to compare the velocity of gas bubbles calculated from Eq. (8) with other models reported in literature. Typical steelmaking slag composition chosen for this purpose is same as mentioned earlier (temperature $1873 \mathrm{~K}$ ) and the variation of bubble velocity with gas void fraction, as calculated from Eq. (8), is shown in Fig. 2.

Ito and Fruehan ${ }^{7)}$ have defined a foaming index $(\Sigma)$ (for gas-slag foam only) as the average residence time of gas bubbles in a gas-slag foam as,

$$
\Sigma=\frac{h}{V_{\mathrm{g}}^{\mathrm{s}}}=\frac{h}{\phi_{\mathrm{g}} \cdot V_{\mathrm{g}}^{\mathrm{JF}}}
$$

where $V_{\mathrm{g}}^{\mathrm{s}}$ is the superficial gas velocity and $V_{\mathrm{g}}^{\mathrm{JF}}$ is the actual bubble velocity. The height of foam, $h$, is given by

$$
h=\frac{W_{\mathrm{s}}}{\rho_{\mathrm{s}}\left(1-\phi_{\mathrm{g}}\right) A}
$$

where $W_{\mathrm{s}}$ is the mass of slag and $A$ is the nominal slag-metal interfacial area. According to Jiang and Fruehan $^{8)}$ the Foaming index, $\Sigma$, depends on viscosity, surface tension and density of slag

$$
\Sigma=\frac{115 \mu_{\mathrm{s}}}{\sqrt{\sigma_{\mathrm{s}} \rho_{\mathrm{s}}}}
$$

From Eqs. (10)-(12)

$$
V_{\mathrm{g}}^{\mathrm{JF}}=\frac{h \sqrt{\sigma_{\mathrm{s}} \rho_{\mathrm{s}}}}{\phi_{\mathrm{g}} 115 \mu_{\mathrm{s}}}=\frac{V_{\mathrm{s}} \sqrt{\sigma_{\mathrm{s}} \rho_{\mathrm{s}}}}{115 A\left(1-\phi_{\mathrm{g}}\right) \mu_{\mathrm{s}} \phi_{\mathrm{g}}}
$$

where $V_{\mathrm{s}}$ is the volume of slag. If the bubble velocity predicted from Eq. (13) is to be compared with Eq. (8), then, as a first approximation it can be assumed that $\rho_{\mathrm{sm}} \sim \rho_{\mathrm{s}},\left(\rho_{\mathrm{sm}}-\rho_{\mathrm{g}}\right) \sim \rho_{\mathrm{s}}$ and $\mu_{\mathrm{sm}} \sim(2 / 3) \mu_{\mathrm{s}}\left(\right.$ since $\left.\phi_{\mathrm{m}}<10^{-4}\right)$.
It can now be seen that the bubble velocity is inversely proportional to viscosity in both the cases (present work and that of Jiang and Fruehan ${ }^{8)}$ ). However, the predictions from Eqs. (8) and (13) are just opposite of each other with respect to the effect of gas void fraction, $\phi_{\mathrm{g}}$, on bubble velocity (Fig. 2); whereas Eq. (8) predicts a continuous decrease in bubble velocity with increase in $\phi_{\mathrm{g}}$ (bubble velocity being proportional to $\left(1-\phi_{\mathrm{g}}^{1 / 3}\right)$ ), Eq. (13) implies a minimum at $\phi_{\mathrm{g}} \sim 0.5$ (bubble velocity being proportional to $1 /\left(\phi_{\mathrm{g}}\left(1-\phi_{\mathrm{g}}\right)\right)$ ). It may be noted that Eq. (8), as originally derived by Gal-Or and Waslo, ${ }^{2)}$ is based on first principles while Eq. (13) is derived from dimensional analysis. In principle, Eq. (8) can be used with a degree of reliability and should be preferred over Eq. (13).

In another approach, Ogawa et al. ${ }^{10)}$ adopted the Wallis model to find the gas void fraction as

$$
\phi_{\mathrm{g}}\left(1-\phi_{\mathrm{g}}\right)=\frac{J}{W_{\alpha}}
$$

where $J$ is superficial velocity of gas phase and $W_{\alpha}$ is the velocity of a single bubble in an infinite medium, i.e.

$$
W_{\alpha}=\frac{\left(\rho_{\mathrm{sm}}-\rho_{\mathrm{g}}\right) g d_{\mathrm{b}}^{2}}{12 \mu_{\mathrm{sm}}}
$$

The gas bubble velocity of an ensemble of bubbles can now be calculated from the expression

$$
V_{\mathrm{g}}^{\mathrm{HG}}=\frac{J}{\phi_{\mathrm{g}}}
$$

On substituting the value of $J$ we get

$$
V_{\mathrm{g}}^{\mathrm{HG}}=\frac{\left(\rho_{\mathrm{sm}}-\rho_{\mathrm{g}}\right) g d_{\mathrm{b}}^{2}}{12 \mu_{\mathrm{sm}}}\left(1-\phi_{\mathrm{g}}\right)
$$

The bubble velocity calculated from Eq. (17) is also plotted in Fig. 2 for the sake of comparison. It is evident from Fig. 2 that trend of variation of bubble velocity calculated from Eqs. (8) and (17) is of similar nature (in contrast with Eq. (13)); according to Eq. (17), the bubble velocity is proportional to $\left(1-\phi_{\mathrm{g}}\right)$ and according to Eq. (8) it is proportional to $\left(1-\phi_{\mathrm{g}}^{1 / 3}\right)$ thereby showing a qualitative agreement between these approaches.

Gou et $a l .{ }^{11)}$ have classified the foaming behavior of slags into two categories: expanded slag and foaming slag. If it is assumed that the gas velocity and gas void fraction are constant throughout the expanded slag and also $\left(\rho_{\mathrm{g}}-\rho_{\mathrm{s}}\right) \simeq \rho_{\mathrm{s}}, \rho_{\mathrm{sg}} \simeq \rho_{\mathrm{s}}\left(1-\phi_{\mathrm{g}}\right)$ and $d V_{\mathrm{g}} / d h \simeq 0$, then superficial gas bubble velocity can be calculated from

$$
\phi_{\mathrm{g}}^{2} /\left(1-\phi_{\mathrm{g}}\right)=0.91\left(V_{\mathrm{g}}^{\mathrm{s}}\right)^{0.573}
$$

According to Eq. (18) bubble velocity is proportional to

$$
\frac{\phi_{\mathrm{g}}^{2.49}}{\left(1-\phi_{\mathrm{g}}\right)^{1.75}}
$$

The bubble velocity calculated from Eq. (18) is also plotted in Fig. 2 as a function of gas void fraction. It is clear that the trend of variation of bubble velocity with gas void fraction obtained from Eq. (8) is opposite to that from Eq. (18). 
Table 1. Functional dependence of bubble velocity on various parameters in different models.

\begin{tabular}{|c|c|c|c|c|}
\hline \multirow[t]{2}{*}{ Factor } & $\begin{array}{l}\text { From Eq. (8) } \\
\text { Gal-Or work }\end{array}$ & $\begin{array}{l}\text { From Eq. (12) } \\
\text { Jiang-Fruehan }\end{array}$ & $\begin{array}{c}\text { From Eq. (17) } \\
\text { Gou et al. }\end{array}$ & $\begin{array}{c}\text { From Eq. (16) } \\
\text { Ogawa et al. }\end{array}$ \\
\hline & \multicolumn{4}{|c|}{ Bubble velocity is proportional to } \\
\hline Density & $\left(\rho_{\mathrm{s}} / \rho_{\mathrm{g}}\right)^{1 / 3}$ & $\sqrt{\rho_{\mathrm{s}}^{*}}$ & - & $\left(\rho_{\mathrm{s}} / \rho_{\mathrm{g}}\right)^{1 / 3}$ \\
\hline $\begin{array}{l}\text { Surface tension } \\
\text { Viscosity }\end{array}$ & $\begin{array}{c}\sigma_{\mathrm{s}} \\
1 /\left(\mu_{\mathrm{s}}\right)\end{array}$ & $\begin{array}{l}\sqrt{\sigma_{\mathrm{s}}} \\
1 / \mu_{\mathrm{s}}\end{array}$ & - & $\begin{array}{c}\sigma_{\mathrm{s}} \\
1 /\left(\mu_{\mathrm{s}}\right)\end{array}$ \\
\hline
\end{tabular}

* for a given volume of slag

** assuming that $\rho_{\mathrm{g}} \ll \rho_{\mathrm{s}}, \rho_{\mathrm{m}}$ and bubble diameter do not change with height

Table 2. Comparison of calculated bubble velocity in foaming slags with the experimental values reported in literature. ${ }^{8-11}$

\begin{tabular}{|c|c|c|c|c|c|c|c|c|c|}
\hline $\begin{array}{c}\text { Slag density } \\
\left(\mathrm{kg} \mathrm{m}^{-3}\right)\end{array}$ & $\begin{array}{c}\text { Surface } \\
\text { tension } \\
\left(\mathrm{kgs}^{-2}\right)\end{array}$ & $\begin{array}{c}\text { Viscosity } \\
\left(\mathrm{kg} \mathrm{m}^{-1} \mathrm{~s}^{-1}\right)\end{array}$ & $\begin{array}{l}\text { Foam } \\
\text { height } \\
\text { (m) }\end{array}$ & $\begin{array}{c}\text { Measured } \\
\text { velocity } \\
\left(\mathrm{ms}^{-1}\right)\end{array}$ & $\begin{array}{l}\text { Estimated } \\
\text { velocity, } \\
\text { present work } \\
\left(\mathrm{m} \mathrm{s}^{-1}\right)\end{array}$ & $\begin{array}{l}\text { Estimated } \\
\text { velocity by } \\
\text { Jiang et al. } \\
\left.\text { (ms }{ }^{-1}\right)\end{array}$ & $\begin{array}{l}\text { Ratio of } \\
\text { present } \\
\text { to Jiang } \\
\text { et al. }\end{array}$ & $\begin{array}{c}\text { Estimated } \\
\text { velocity by } \\
\text { Ogawa et al. }{ }^{10)} \\
\left(\mathrm{m} \mathrm{s}^{-1}\right)\end{array}$ & $\begin{array}{l}\text { Estimated } \\
\text { velocity by } \\
\text { Gou et al. }{ }^{(1)} \\
\left(\mathrm{m} \mathrm{s}^{-1}\right)\end{array}$ \\
\hline 3042.00 & 0.572 & 0.228 & 0.350 & 0.646 & 0.418 & 0.616 & 0.678 & 1.211 & 50.434 \\
\hline 3092.00 & 0.576 & 0.202 & 0.343 & 0.762 & 0.475 & 0.693 & 0.686 & 1.376 & 50.434 \\
\hline 3142.00 & 0.578 & 0.160 & 0.337 & 0.750 & 0.591 & 0.868 & 0.690 & 1.712 & 50.434 \\
\hline 3123.00 & 0.576 & 0.132 & 0.340 & 0.686 & 0.718 & 1.054 & 0.681 & 2.080 & 50.434 \\
\hline 3265.00 & 0.585 & 0.113 & 0.322 & 0.721 & 0.852 & 1.214 & 0.702 & 2.469 & 50.434 \\
\hline
\end{tabular}

Note 1: The master slag containing $69 \% \mathrm{CaO}, 23 \% \mathrm{SiO}_{2}$ and $8 \% \mathrm{MgO}$ to which different amounts of FeO and $\mathrm{MnO}$ are added; experiments in alumina crucibles and final $\mathrm{Al}_{2} \mathrm{O}_{3}$ content upto $18 \%$; temperature $1773 \mathrm{~K}$, area of crucible $0.00132 \mathrm{~m}^{2}$, mass of slag $0.14 \mathrm{~kg}$, bubble diameter assumed $0.033 \mathrm{~m}$, and gas void fraction 0.9 .

Note 2: In the last columns estimated velocity, according to Gou et al., ${ }^{11}$ depends only on gas void fraction and it is same for all cases.

Table 3. Comparison of calculated bubble velocity in foaming slags with the experimental values reported in literature. ${ }^{8-11)}$

\begin{tabular}{cccccccccc}
\hline $\begin{array}{c}\text { Slag density } \\
\left(\mathrm{kg} \mathrm{m}^{-3}\right)\end{array}$ & $\begin{array}{c}\text { Surface } \\
\text { tension } \\
\left(\mathrm{kg} \mathrm{s}^{-2}\right)\end{array}$ & $\begin{array}{c}\text { Viscosity } \\
\left(\mathrm{kg} \mathrm{m}^{-1} \mathrm{~s}^{-1}\right)\end{array}$ & $\begin{array}{c}\text { Foam } \\
\text { height } \\
(\mathrm{m})\end{array}$ & $\begin{array}{c}\text { Measured } \\
\text { velocity } \\
\left(\mathrm{m} \mathrm{s}^{-1}\right)\end{array}$ & $\begin{array}{c}\text { Estimated } \\
\text { velocity, } \\
\text { present work } \\
\left(\mathrm{m} \mathrm{s}^{-1}\right)\end{array}$ & $\begin{array}{c}\text { Estimated } \\
\text { velocity by } \text { bet al. } \\
\left(\mathrm{m} \mathrm{s}^{-1}\right)\end{array}$ & $\begin{array}{c}\text { Ratio of } \\
\text { present } \\
\text { to Jiang } \\
\text { et al. }\end{array}$ & $\begin{array}{c}\text { Estimated } \\
\text { velocity by } \\
\text { Ogawa } \text { et al. } .^{10)} \\
\left(\mathrm{m} \mathrm{s}^{-1}\right)\end{array}$ & $\begin{array}{c}\text { Estimated } \\
\text { velocity by } \\
\text { Gou } \text { et al. } .^{11)} \\
\left(\mathrm{m} \mathrm{s}^{-1}\right)\end{array}$ \\
\hline 3000.00 & 0.565 & 0.114 & 0.212 & 0.783 & 0.807 & 0.738 & 1.093 & 2.338 & 50.434 \\
3056.00 & 0.569 & 0.099 & 0.208 & 0.769 & 0.932 & 0.845 & 1.102 & 2.701 & 50.434 \\
3115.00 & 0.572 & 0.086 & 0.204 & 0.754 & 1.074 & 0.966 & 1.111 & 3.112 & 50.434 \\
\hline
\end{tabular}

Note: The master slag containing $69 \% \mathrm{CaO}, 23 \% \mathrm{SiO}_{2}$ and $8 \% \mathrm{MgO}$ to which different amounts of $\mathrm{FeO}$ and $\mathrm{MnO}$ are added; other conditions are same as mentioned at the bottom of Table 2 .

For the sake of easy comparison of all the approaches, the predicted effects of various parameters on bubble velocity are summarized in Table 1 . It can be seen that the predicted effects of surface tension, density, viscosity and gas void fraction on bubble velocity are fundamentally of same nature for the present work and that for Ogawa et al., but they differ considerably from the works of others which are based either on dimensional analysis or on empirical formulae.

Roth et al. ${ }^{9)}$ carried out laboratory experiments at $1773 \mathrm{~K}$ and some of their results are summarized in Tables 2 and 3. Predictions from Eqs. (8), (13), (17) and (18) are also summarized in Tables 2 and 3 . In calculating the bubble velocity values, as listed in Tables 2 and 3 , $\phi_{\mathrm{g}}$ was assumed to be approximately 0.9 on the basis of initial and final foam heights achieved in the laboratory experiment of Roth et al. ${ }^{9)}$

Although the predictions from Eq. (8) happen to be in qualitative agreement (in order of magnitude) with the predictions from Eq. (13) (see Tables 2 and 3 for comparison), Eq. (8) is theoretically correct and should be used, preferably with some factor for adaptation to specific experimental conditions. Estimated bubble velocities from Eq. (17) are higher by a factor of 2-3 while those from Eq. (18) are higher by a factor of approximately 60 (vis a vis the experimentally observed values).

Extensive experiments are required in the lower ranges of $\phi_{\mathrm{g}}(0.30$ to 0.6$)$ to confirm the applicability of models because, at present, almost no experimental data exist in this range for steel making slags.

\section{Emulsion Number as an Indicator of Slopping}

In order to calculate Emulsion number, Eq. (8) is employed for calculating $V_{\mathrm{g}}$ and Eqs. (2), (3) and (6) are 


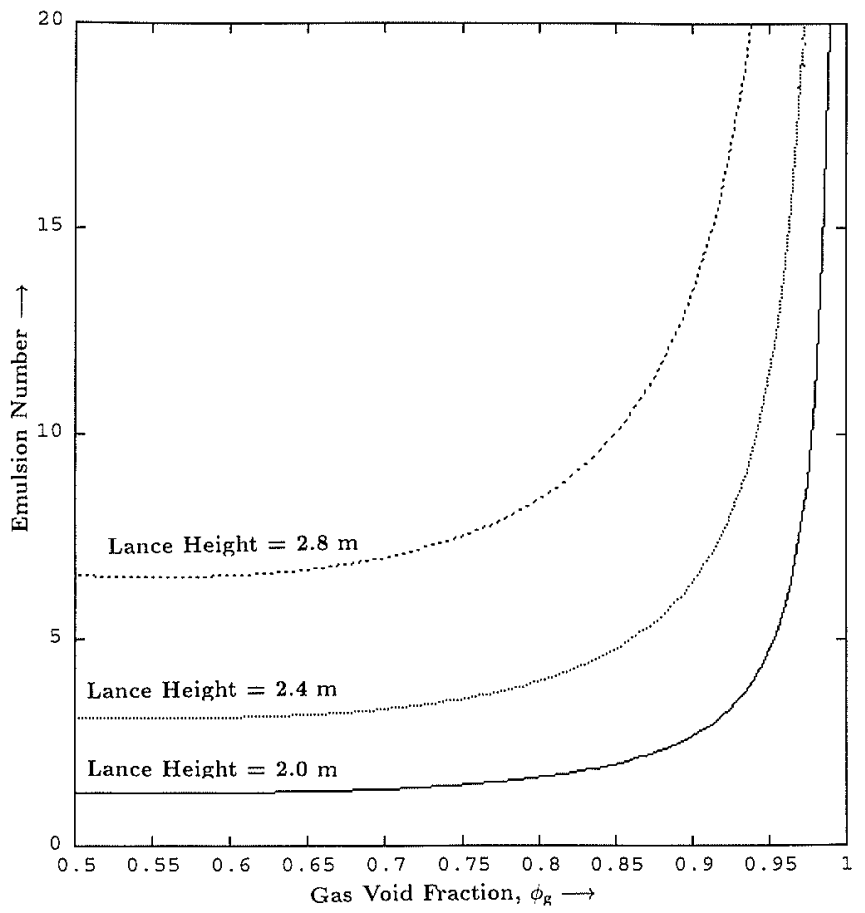

Fig. 3. Calculated values of Emulsion number at different gas void fractions for constant lance heights 2, 2.5 and $2.8 \mathrm{~m}$ for nozzle design of plant $\mathrm{B}$ in Table 5 .

used for obtaining $V_{\mathrm{d}}$. Emulsion number depends, amongst other things, on lance height and gas void fraction. The values of En calculated in this work are higher by a factor of nearly hundred $(\psi \simeq 100)$ as compared to our previous work primarily because of characteristic values of droplet velocity.

Emulsion number has a practical utility. A plot of En versus $\phi_{\mathrm{g}}$ at different lance heights shows (Fig. 3) that En is nearly constant for low values of $\phi_{\mathrm{g}}$ and after a slight minima at around $\phi_{\mathrm{g}}=0.55$, it increases at a rapid rate. A sudden rise in En at high gas void fraction actually indicates the tendency of the system for slopping. As discussed later, Emulsion number can be incorporated in the dynamic model of converter to predict in advance the likelihood of slopping. It can also be used to compare the expected performance of different nozzles designs for slopping behavior. Analysis of operational data has revealed that Emulsion number can be related to the rate of lime dissolution in slag. Thus for a given set of operating conditions, an empirical equation can be derived to predict lime dissolution rate in terms of Emulsion number.

\section{Dynamic Model for Slag Foaming in Converter}

Three distinct periods (or regimes) of decarburization are observed during the blow in a converter ${ }^{6)}$ : (1) initial blow period of 3-5 min during which decarburization increases linearly with time; (2) the main blow of approximately $10 \mathrm{~min}$ in which decarburization rate is nearly constant and gas $\left(\mathrm{CO}+\mathrm{CO}_{2}\right)$ production rate is maximum; (3) the end blow period in which decarburization rate initially drops linearly and then asymptotically. In this work we are concerned with foaming and slopping of slag which occurs primarily in the middle blow period.
The CO gas is produced due to oxidation of carbon in the jet impact zone and a part (approximately 15-20\% by volume) of this is oxidized to $\mathrm{CO}_{2}$. The retention of gas bubbles in the slag increases the height of the foam. If this foaming is excessive then slopping is likely to occur.

According to stoichiometry of the chemical reaction, two moles of $\mathrm{CO}$ gas are produced for every mole of oxygen. If the oxygen supply rate (at NTP) is $F_{\mathrm{O}}$ then the $\mathrm{CO}$ gas generation rate, $F_{\mathrm{CO}}$, at temperature $T$ and ambient pressure, $1.35 \mathrm{~atm}$. is given by the relation

$$
\frac{2 P_{\mathrm{at}} F_{\mathrm{O}_{2}}}{273}=\frac{1.35 \times 10^{5} F_{\mathrm{CO}}}{T}
$$

Approximately $15-20 \%$ of the $\mathrm{CO}$ gas gets oxidized to $\mathrm{CO}_{2}$ and this leads to a decrease in the gas volume. Further, a small part of the gas may not pass through the foam and escape directly. Let $\alpha$ be the effective fraction of gas (it includes the fraction of $\mathrm{CO}$ oxidised to $\mathrm{CO}_{2}$ ) which passes through the foam. If $V_{\mathrm{G}}^{i}$ is the gas volume in the foam at the start of the main blow period and $\tau_{\mathrm{b}}$ is average residence time of bubbles then

$$
\alpha \tau_{\mathrm{b}} F_{\mathrm{CO}}=V_{\mathrm{G}}^{\mathrm{i}}
$$

From Eqs. (8) and (11) we get

$$
\tau_{\mathrm{b}}=\frac{h}{V_{\mathrm{g}}}=\frac{\frac{W_{\mathrm{s}}}{\rho_{\mathrm{s}}\left(1-\phi_{\mathrm{g}}\right) A}}{\left[\frac{\left(\rho_{\mathrm{sm}}-\rho_{\mathrm{g}}\right) g d_{\mathrm{b}}^{2}\left(1-\phi_{\mathrm{g}}^{1 / 3}\right)}{12 \mu_{\mathrm{sm}}}\right]}
$$

Also,

$$
V_{\mathrm{G}}^{\mathrm{i}}=\frac{W_{\mathrm{s}}}{\rho_{\mathrm{s}}\left(1-\phi_{\mathrm{g}}\right)} \phi_{\mathrm{g}}
$$

From Eqs. (20)-(22) we get

$$
\frac{12 \alpha \mu_{\mathrm{sm}} F_{\mathrm{CO}}}{A\left(\rho_{\mathrm{sm}}-\rho_{\mathrm{g}}\right) g d_{\mathrm{b}}^{2}}=\phi_{\mathrm{g}}\left(1-\phi_{\mathrm{g}}^{1 / 3}\right)
$$

Equation (23) is nonlinear in $\phi_{\mathrm{g}}$ and is plotted Fig. 4 where it can be seen that for a given value of $F_{\mathrm{CO}}$ there are two possible values of $\phi_{\mathrm{g}}$ which satisfy Eq. (23). However, of the two values, only the smaller value of $\phi_{\mathrm{g}}$ is to be accepted because of the physical requirements that $\phi_{\mathrm{g}}=0$ when $F_{\mathrm{CO}}=0$ and $\phi_{\mathrm{g}}$ should increase with $\alpha$ as well as $F_{\mathrm{CO}}$. Let the smaller value be denoted by $\phi_{\mathrm{g}}^{\mathrm{i}}$ (this also corresponds to $V_{\mathrm{G}}^{i}$ ).

The stipulated mechanism of slopping is as follows. It is practically observed that $\mathrm{FeO}$ content of slag steadily increases with time in the first blow period but as soon as the main blow starts the reduction of $\mathrm{FeO}$ in the slag by metal droplets begins and additional $\mathrm{CO}$ gas is produced. The overall reaction for reduction of $\mathrm{FeO}$ is: $(\mathrm{FeO})+[\mathrm{C}] \rightarrow\{\mathrm{Fe}\}+(\mathrm{CO})_{\mathrm{g}}$. The additional $\mathrm{CO}$ gas thus produced enhances the gas void fraction of slag. The subsequent effects are cumulative. For example, increase in gas void fraction leads to increase in foam height and the increase in foam height in turn increases the residence time of metal droplets in slag which eventually enhance the rate of reduction of $\mathrm{FeO}$, and so on. A situation may arise when the foam height is much more than the converter can accommodate and hence slopping is likely 




Fig. 4. Function value computed from Eq. (23) at different gas void fractions; solid line at top indicates the maximum possible value of LHS of Eq. (23).

to occur. According to this mechanism if the total gas volume in slag at any instant is $V_{\mathrm{G}}$ then during a small time step $\Delta t$

$$
V_{\mathrm{G}}=V_{\mathrm{G}}^{\mathrm{i}}+V_{\mathrm{G}, \mathrm{d}}-V_{\mathrm{G}, \mathrm{d}}^{\mathrm{e}}
$$

where $V_{\mathrm{G}, \mathrm{d}}$ is the total volume of gas generated due to droplet-slag reaction and $V_{\mathrm{G}, \mathrm{d}}^{\mathrm{e}}$ is the volume that escapes. Now,

$$
\begin{aligned}
V_{\mathrm{G}, \mathrm{d}}(\text { at time } t+\Delta t)= & V_{\mathrm{G}, \mathrm{d}}(\text { at time } t) \\
& +\left(\frac{d n_{\mathrm{FeO}}}{d t} \frac{R T}{p_{\mathrm{CO}}} \Delta t\right)
\end{aligned}
$$

As discussed elsewhere ${ }^{1,12)}$ the reduction rate of $\mathrm{FeO}$ in slag by carbon present in metal droplets can be calculated from

$$
-\frac{d n_{\mathrm{FeO}}}{d t}=\lambda\left[\frac{6 k_{\mathrm{o}} M g h a_{\mathrm{FeO}} p_{\mathrm{CO}}}{V_{\mathrm{d}} \rho_{\mathrm{m}} d_{\mathrm{m}}}\right]
$$

where the rate constant $k_{\mathrm{o}}$ is

$$
k_{\mathrm{o}}=\frac{1}{\frac{1}{k_{2}}+\frac{1}{k_{3 \mathrm{a}} K}}
$$

Thus we get

$$
V_{\mathrm{G}, \mathrm{d}}^{\mathrm{c}}(\text { at time } t)=V_{\mathrm{G}, \mathrm{d}}(\text { at time } t) \frac{\Delta t}{\tau_{\mathrm{b}}}
$$

At the start of the main blow the initial value of $\phi_{\mathrm{g}}$ may be taken as the peak value in Fig. 4 to investigate the maximum likelihood of slopping in a blow. Further, the factor $\lambda$ in Eq. (26) is adjusted to simulate (by trial and error) the effective area of droplet-slag reaction so as to
Table 4. Slag compositions obtained at different time (indicated as percent of total blow period).

\begin{tabular}{lccccc}
\hline$\%$ time & $\begin{array}{c}\mathrm{CaO} \\
(\%)\end{array}$ & $\begin{array}{c}\mathrm{FeO} \\
(\%)\end{array}$ & $\begin{array}{c}\mathrm{SiO}_{2} \\
(\%)\end{array}$ & $\begin{array}{c}\text { Bath } \\
\text { weight } \\
(\mathrm{kg})\end{array}$ & $\begin{array}{c}T \\
\left({ }^{\circ} \mathrm{C}\right)\end{array}$ \\
\hline 25 & 37.8 & 33.5 & 28.7 & 17353 & 1429 \\
29 & 39.0 & 32.0 & 30.0 & 17647 & 1460 \\
32 & 40.0 & 30.7 & 29.3 & 17647 & 1481 \\
36 & 41.6 & 28.9 & 29.5 & 17941 & 1491 \\
39 & 43.2 & 26.8 & 30.0 & 17941 & 1499 \\
43 & 45.0 & 24.6 & 30.4 & 17941 & 1496 \\
46 & 47.2 & 22.8 & 30.0 & 18088 & 1491 \\
50 & 49.0 & 21.5 & 29.5 & 17941 & 1486 \\
54 & 50.2 & 20.2 & 29.6 & 17941 & 1481 \\
57 & 52.0 & 19.5 & 28.5 & 17941 & 1481 \\
61 & 53.6 & 18.7 & 27.7 & 17647 & 1481 \\
64 & 54.6 & 18.2 & 27.2 & 17941 & 1486 \\
68 & 55.8 & 19.3 & 24.9 & 17941 & 1499 \\
71 & 56.2 & 20.1 & 23.7 & 17941 & 1502 \\
75 & 56.3 & 21.4 & 22.3 & 18235 & 1522 \\
79 & 55.3 & 23.2 & 21.5 & 18823 & 1538 \\
82 & 55.0 & 24.2 & 20.4 & 19412 & 1558 \\
86 & 54.0 & 26.3 & 19.7 & 20000 & 1584 \\
89 & 52.7 & 28.6 & 18.7 & 20882 & 1620 \\
93 & 51.3 & 30.6 & 18.1 & 21765 & 1656 \\
\hline
\end{tabular}

Table 5. Lance head design parameters of three steel plants.

\begin{tabular}{llccc}
\hline Parameters & (units) & Plant A & Plant B & Plant C \\
\hline$F_{\mathrm{O}_{2}}$ & $\left(\mathrm{~m}^{3} / \mathrm{min}\right)$ & 900 & 915 & 900 \\
$p_{\mathrm{o}}$ & $(\mathrm{atm})$ & 11.6 & 10.8 & 11.0 \\
$d_{1}$ & $(\mathrm{~mm})$ & 48.44 & 45.2 & 40.6 \\
$d_{\mathrm{c}}$ & $(\mathrm{mm})$ & 63.0 & 61.3 & 57.75 \\
$\theta($ deg$)$ & $(\mathrm{deg})$ & 12 & 14 & 14 \\
Number of nozzles & & 4 & 5 & 6 \\
Bath weight & $(\mathrm{t})$ & 330 & 315 & 300 \\
\hline
\end{tabular}

follow/reproduce the actual slag path in a converter. Typical slag compositions for a $300 \mathrm{t}$ converter as a function of blowing time are given in Table 4 and for this slag path the value of $\lambda$ in the main blow period was found to be 0.25 . From the Eqs. (3) and (26), assuming other things to be constant, we get

$$
\begin{aligned}
\frac{d n_{\mathrm{FeO}}}{d t} & \propto \frac{M g}{V_{\mathrm{d}} d_{\mathrm{m}}} \propto \frac{M g}{d_{\mathrm{m}}^{3}} \\
& \propto\left[\left(\frac{x}{d_{\mathrm{t}}}\right)^{2.412}\right]^{3} M g=M g\left(\frac{x}{d_{\mathrm{t}}}\right)^{7.236}
\end{aligned}
$$

For a given throat diameter, $M g$ is, approximately, inversely proportional to the square of lance height $\left(x^{-2}\right)$.

It can be inferred from Eq. (28) that both throat diameter (hence nozzle design) and lance height influence the $\mathrm{FeO}$ reduction rate; for a given throat diameter $d_{\mathrm{t}}$, the reduction rate of $\mathrm{FeO}$ increases as the lance height $(x)$ increases. This is why the lance height is reduced in the main blow period to avoid slopping. For nozzle design A given in Table 5 and the slag compositions given in Table 4, the calculated value of $\phi_{\mathrm{g}}$ is plotted against time for three different lance heights in Fig. 5 and it can be seen that $\phi_{\mathrm{g}}$ also increases when lance height is increased. For the sake of comparison the maximum allowable gas 


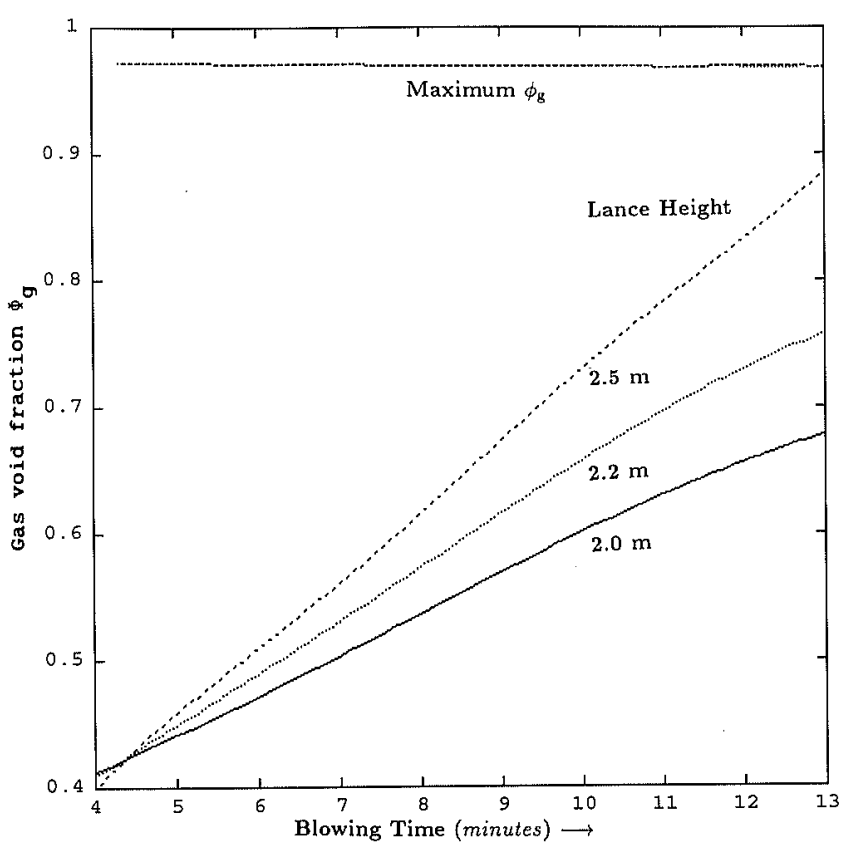

Fig. 5. Gas void fraction vs. time at different lance heights. (Plant B nozzle design in Table 5)

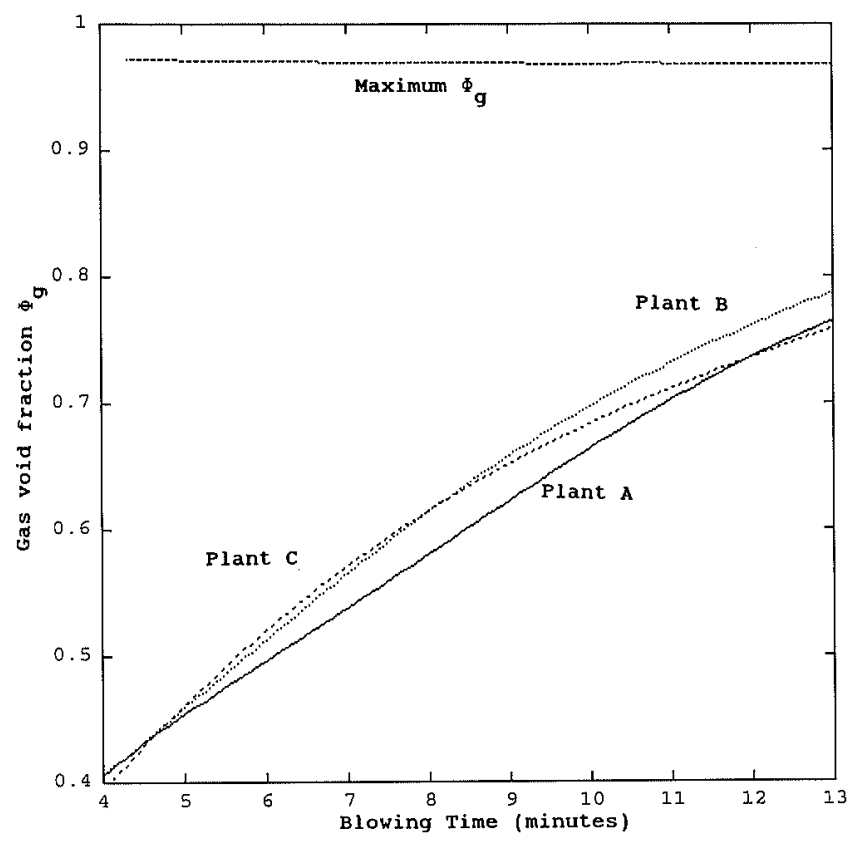

Fig. 6. Comparison of gas void fraction vs. time curves for different lance tips used at Plants A, B and C (Table 5) at a fixed lance height. ${ }^{6}$

void fraction for a converter is given by

$$
\phi_{\mathrm{g}}^{\max }=1-\frac{V_{\mathrm{s}}}{V_{\mathrm{c}}-V_{\mathrm{m}}}
$$

The value of $\phi_{\mathrm{g}}^{\max }$ is also plotted in Fig. 5 to show the upper limit of gas void fraction beyond which slopping will occur. Figure 6 compares the plot of $\phi_{\mathrm{g}}$ versus time for three different nozzle designs (listed in Table 5) and the corresponding blowing regimes (Fig. 7) actually followed in steel plants. ${ }^{6)}$ If the slag composition (or slag path) is assumed to be the same as in Table 4 for all the three cases, then according to Fig. 6 the combination of nozzle design and the blowing regimes is such that the

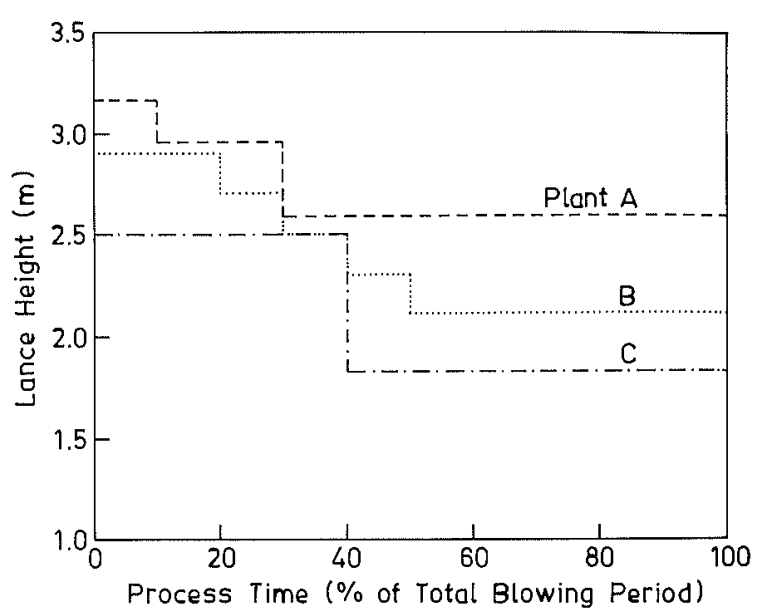

Fig. 7. Typical blowing regimes ${ }^{6}$ (variation of lance height with blowing time) at plants $\mathrm{A}, \mathrm{B}$ and $\mathrm{C}$.

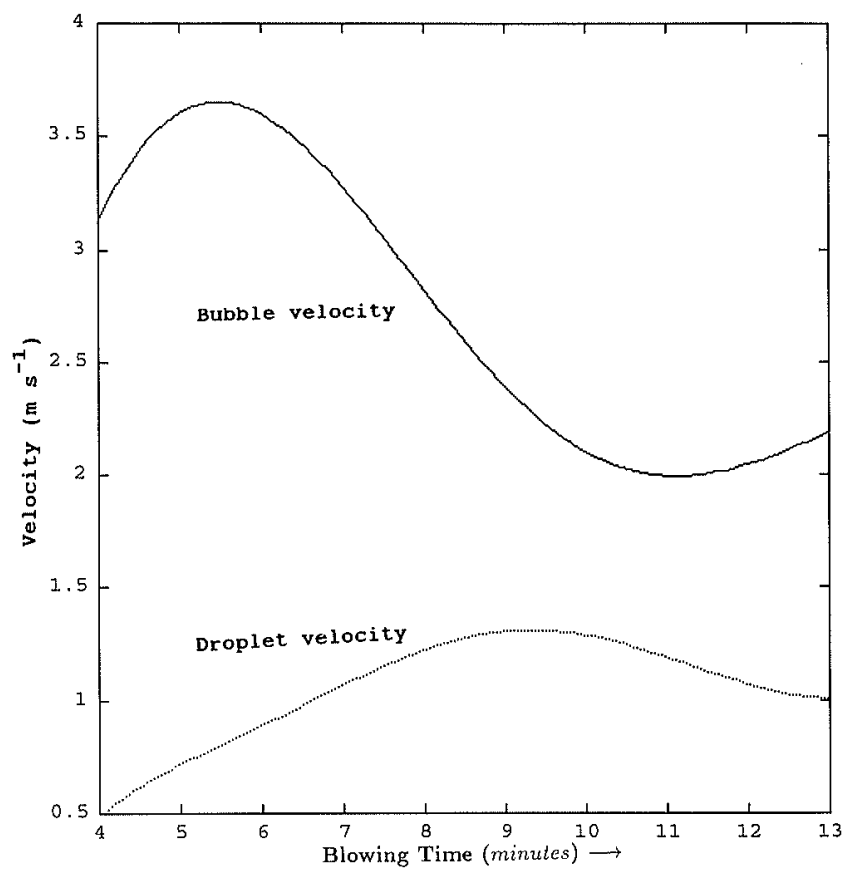

Fig. 8. Variation of gas bubble and metal droplet velocities $v s$. time in the middle blow period (25-75\% of blowing time) for plant $B$.

possibility of slopping will be small in all the three plants.

We have not incorporated the effect of precipitation/dissolution of solid dicalcium silicate in slag on the viscosity of slag at different stages of the blow. This can however be done simply by using KapoorFrohberg model to calculate the amount of dicalcium silicate precipitation and then using Eq. (5) or any such other equation to calculate the corresponding slag viscosity.

The calculated bubble and metal droplet velocities for plant B are plotted in Fig. 8; while the variations in bubble velocity are primarily due to changes in temperature and $\phi_{\mathrm{g}}$ at different stages of the blow, droplet velocity is strongly influenced by lance nozzle design and lance height because it affects the droplet diameter.

The above procedure of estimating the droplet velocity, bubble velocity, $\mathrm{FeO}$ reduction rate, $\phi_{\mathrm{g}}$, foam height etc., has been demonstrated when the slag composition is 
known a priori. In an actual converter practice, it will be therefore ideal to combine the dynamic slag foaming model with dynamic converter model so that the temperature and composition of metal and slag can be fed on line to the slag foaming model and vice versa. Even if a full scale dynamic converter control model is not operational at a plant, an approximate slag path can be predicted by relating the emulsion number to lime dissolution rate and combining the scrap dissolution model with the decarburization model and the $\mathrm{FeO}$ reduction rate model to perform simultaneous heat and mass balance.

\section{Conclusions}

Calculation of residence time of metal droplets and gas bubbles in slag has been one of the most significant and intriguing aspects of steel making. The approach presented in this paper has a strong theoretical basis. The predicted values of bubble velocity agree with experimental values at high gas void fraction in slag $\left(\phi_{\mathrm{g}}>0.8\right)$, but further experiments are needed at low gas void fractions to demonstrate the applicability of this model over wide range of conditions. Emulsion number can be used to analyze slopping behavior under steelmaking conditions. Dynamic slag foaming model developed in this work is successfully applied for a given slag path to three different converters for which the nozzle designs as well as blowing regimes are known. In an overall scheme, dynamic slag foaming model will become an integral part of the dynamic converter control model.

\section{Nomenclature}

$a_{\mathrm{FeO}}$ : Activity of $\mathrm{FeO}$ in slag

$A$ : Cross sectional area of the converter $\left(\mathrm{m}^{2}\right)$

$d_{\mathrm{b}}$ : Diameter of a bubble $(\mathrm{m})$

$d_{\text {lim }}$ : Upper limiting size of metal droplets $(\mathrm{m})$

$d_{\mathrm{m}}$ : Diameter of droplet $(\mathrm{m})$

$d_{1}$ : Throat diameter of lance nozzle $(\mathrm{m})$

En: Emulsion number (dimensionless)

$F_{\mathrm{CO}}$ : Carbon monoxide gas production rate $\left(\mathrm{m}^{3} \mathrm{~s}^{-1}\right)$

$F_{\mathrm{O}_{2}}$ : Oxygen supply rate from lance $\left(\mathrm{m}^{3} \mathrm{~s}^{-1}\right)$

$h$ : Foam height $(\mathrm{m})$

$k$ : Constant (depends on temperature) $\left(\mathrm{mol} \mathrm{m}^{-2} \mathrm{~s}^{-1} \mathrm{~Pa}^{-1}\right)$

$M g$ : Iron conversion $\left(\mathrm{kg} \mathrm{s}^{-1}\right)$

$p_{\text {at }}$ : Ambient pressure $(\mathrm{Pa})$

$p_{\mathrm{CO}}:$ Partial pressure of $\mathrm{CO}$ in gas phase $(\mathrm{Pa})$

$p_{\mathrm{O}}$ : Supply pressure of $\mathrm{CO}$ in gas phase $(\mathrm{Pa})$

$R$ : Universal gas constant $\left(\mathrm{J} \mathrm{mol}^{-1} \mathrm{~K}^{-1}\right)$

$t:$ Time (s)

$\alpha$ : Fraction of gas actually passing through the foam

$\tau_{\mathrm{d}}:$ Residence time of metal droplets (s)

$\tau_{\mathrm{b}}$ : Mean residence time of gas bubbles in slag (s)

$V_{\mathrm{g}}^{\mathrm{s}}$ : Superficial gas velocity $(\mathrm{m} / \mathrm{s})$

$V_{\mathrm{g}}$ : Rising velocity of gas bubbles in slag $\left(\mathrm{m} \mathrm{s}^{-1}\right)$

$V_{G}$ : Total volume of gas entrapped in slag at any instant $\left(\mathrm{m}^{3}\right)$

$V_{\mathrm{G}, \mathrm{d}}$ : Total volume of gas generated due to droplet slag reaction $\left(\mathrm{m}^{3}\right)$

$V_{\mathrm{G}, \mathrm{d}}^{\mathrm{e}}$ : Volume of gas (generated by droplet-slag reaction) which escapes from converter in given time step $\left(\mathrm{m}^{3}\right)$

$V_{\mathrm{G}}^{\mathrm{i}}$ : Volume of gas entrapped at the start of middle blow $\left(\mathrm{m}^{3}\right)$

$V_{\mathrm{d}}$ : Settling velocity of metal droplets in gas-slag mixture $\left(\mathrm{ms}^{-1}\right)$

$V_{\mathrm{g}}^{\mathrm{JF}}$ : Bubble velocity according to Jiang and Fruehan $^{8)}\left(\mathrm{m} \mathrm{s}^{-1}\right)$

$V_{\mathrm{g}}^{\mathrm{HG}}$ : Bubble velocity according to Ogawa et al. ${ }^{10)}$ $\left(\mathrm{m} \mathrm{s}^{-1}\right)$

$V_{\mathrm{s}}: \quad$ Volume of slag phase $\left(\mathrm{m}^{3}\right)$

$V_{\mathrm{m}}$ : Volume of metal phase $\left(\mathrm{m}^{3}\right)$

$V_{\mathrm{c}}$ : Available volume of converter $\left(\mathrm{m}^{3}\right)$

$W_{\mathrm{s}}$ : Mass of slag $(\mathrm{kg})$

$x$ : Lance height $(\mathrm{m})$

$\xi$ : Friction factor (dimensionless)

$\theta$ : Angle of the divergent part of the nozzle (radians)

$\mu_{i}$ : Viscosity of phase $i\left(\mathrm{~kg} \mathrm{~m}^{-1} \mathrm{~s}^{-1}\right)$

$\rho_{i}$ : Density of phase $i\left(\mathrm{~kg} \mathrm{~m}^{-3}\right)$

$\sigma_{i}:$ Surface tension of phase $i\left(\mathrm{~kg} \mathrm{~s}^{-2}\right)$

$\phi_{i}$ : Volume fraction of phase $i$ in gas-metal-slag emulsion (dimensionless)

$\phi_{\max }:$ Maximum attainable concentration (expressed as fraction)

$\Sigma$ : Foaming index (s)

Subscripts

$\begin{aligned} \mathrm{g}: & \text { gas phase } \\ \mathrm{m}: & \text { metal phase } \\ \mathrm{s}: & \text { slag phase } \\ \mathrm{sm}: & \text { slag-metal continuous phase } \\ \mathrm{sg}: & \text { slag-gas continuous phase } \\ \mathrm{ef}: & \text { effective value of solid-liquid continuous } \\ \text { property } & \\ \text { 1: } & \text { liquid }\end{aligned}$

\section{REFERENCES}

1) B. Deo, A. Karamchetti, A. Paul, P. Singh and R. P. Chhabra: ISIJ Int., 36 (1996), 658.

2) B. Gal-Or and S. Waslo: Chem. Eng. Sci., 23 (1968), 1431.

3) S. C. Koria and K. W. Lange: Ironmaking Steelmaking, 13 (1968), 236.

4) K. Schwerdtfeger: Kinetics of Metallurgical Processes, ed. by K. W. Lange, Verlag Stahleisen MBH, Dusseldorf, (1975), 192.

5) H. Eilers: Kolloidn Zh., 97 (1941), 313.

6) B. Deo and R. Boom: Fundamentals of Steelmaking Metallurgy, Prentice Hall Int., (1993).

7) K. Ito and R. J. Fruehan: Metall. Trans., 20B (1989), 151

8) R. Jiang and R. J. Fruehan: Metall. Trans., 22B (1991), 481.

9) R. E. Roth, R. Jiang and R. J. Fruehan: Iron Steelmaker, Trans. ISS, Nov. (1992), 55.

10) Y. Ogawa, D. Huin, H. Gaye and N. Tokumitsu: ISIJ Int, 33 (1993), 224.

11) H. Gou, G. A. Irons and W. K. Lu: Metall Mater. Trans, 27B (1996), 195

12) A. Paul, B. Deo and N. Satyamurthy: Steel Res., 65 (1994), 414. 